\title{
HISTOPATHOLOGYC CHARACTERIZATION OF DIFFERENTIATED THYROID CARCINOMA IN AN AREA OF THE BASQUE COUNTRY
}

M.A. Vicente Vicente, P. Sierra Polo, C. Cabrejas Gómez, I. Olaizola Iregui, N. Gozález Cabrera, C.R. Fuentes Gómez, M.A. Antón Miguel Servicio de Endocrinología y Nutrición. Hospital Universitario Araba (Txagorritxu). Vitoria-Gasteiz (Spain).

\section{BACKGROUND}

The most common type of thyroid cancer is the well-differentiated thyroid carcinoma (DTC), and that includes papillary (PTC) and follicular carcinoma (FTC). The PTC would represent $50-90 \%$ and the FTC over $15-30 \%$. Within the PTC, the most frequent is the classical variant (over $80 \%$ ), followed by follicular variant $(10 \%)$ and the rest of variants $(<10 \%)$. Furthermore, there are differences between PTC and FTC in age at diagnosis, local extension, multicentricity and the presence or absence of lymphadenopathy.

Our aim was to analyze the prevalence of the different variants of CDT in an area of the Basque Country and the histopathologic characteristics of the sample.

\section{METHODOLOGY}

We studied the medical records of 110 patients diagnosed with differentiated thyroid cancer, obtained from hospital tumor registry between the years 2005-2012. Using SPSS we performed a descriptive analysis of the sample and compared means.

RESULTS:

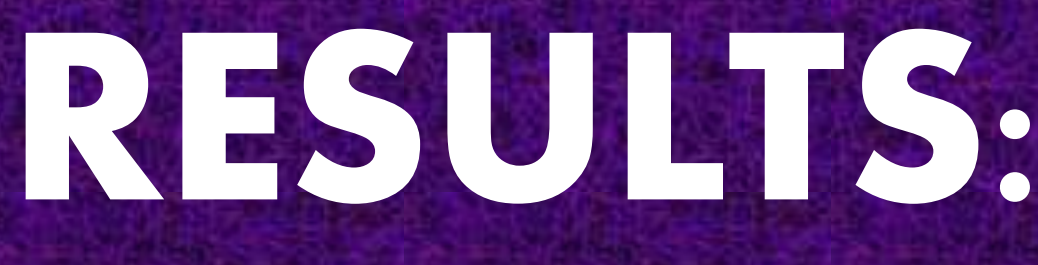

\[ \mathrm{N}=110 \]
Age at diagnosis
Average size
Multicentricity
Dedifferentiation
Local extension
Lymphadenopathy



Classical variant

Follicular variant

Diffuse sclerosing

D High cell

口 Columnar cell

Clear cell

Mixed

No significant differences among the different histotypes of each group in terms of age at diagnosis and tumor size were found. There was also no correlation between size and age at diagnosis.

\section{CONCLUSIONS:}

-Unlike described by the literature, the follicular variant PTC is more frequent in our area.

-Tumor size at diagnosis in the FTC is significantly higher than in the PTC.

-The PTC was presented with lymphadenopathy at diagnosis in a rate of $20 \%$, unlike the FTC. 